\title{
Intraocular pressure response to corticosteroids in children
}

\author{
BEN-ZION BIEDNER, ROBERT DAVID, ALEXANDER GRUDSKY, AND \\ URIEL SACHS \\ From the Department of Ophthalmology, Soroka Medical Center, Faculty of Health Sciences, \\ Ben Gurion University of the Negev, Beer-Sheva, Israel
}

SUMmARY A total of 44 children who suffered from vernal conjunctivitis were treated with topical dexamethasone $0 \cdot 1 \% 4$ times daily for 6 weeks and tested for their intraocular pressure. There was a statistically significant difference $(P<0.01)$ between the responders in our group of children and a group of normal adults reported on by Armaly in 1965.

Topically administered corticosteroids are widely used in treating a large range of inflammatory and allergic eye conditions. But their use has been partially limited after Armaly ${ }^{1}$ reported the increase in intraocular pressure (IOP) produced by locally instilled corticosteroids. The 'corticosteroid response' was found by Armaly ${ }^{1}$ after subjecting a sample of normal population to topical corticosteroid instillation and monitoring the increase in their IOP. According to the increase in the IOP, 3 categories of response are distinguished in the normal adult population: low $(66 \cdot 2 \%)$, intermediate $(28.8 \%)$, and high $(5 \%)$. Furthermore, Armaly ${ }^{2}$ found that the steroid response is hereditary.

To the best of our knowledge there are no published data on the pressure-raising effect of topically administered steroids in children from families free from glaucoma.

\section{Materials and methods}

In the present study we are reporting the influence of topically administered corticosteroids on the intraocular pressure in children treated for vernal conjunctivitis.

Forty-four children were diagnosed as suffering from this disease and needed treatment with topical steroids. There were 32 boys and 12 girls, whose ages ranged from 4 to 19 years, average of 9.7 years. None of them were treated with steroid, topically or systematically, for at least 4 weeks. The treatment was identical in all cases: Dexamethasone phosphate

Correspondence to B. Biedner, MD, Department of Ophthalmology, Soroka Medical Center, PO Box 151, Beer-Sheva, Israel.
Table 1 Corticosteroid test in normal patients

\begin{tabular}{llll}
\hline $\begin{array}{l}\text { Increase in } \\
\text { intraocular } \\
\text { pressure } \mathrm{mmHg}\end{array}$ & & $\begin{array}{l}\text { Our } \\
\text { results } \\
(44 \text { children })\end{array}$ & $\begin{array}{l}\text { Armaly's } \\
\text { results } \\
(80 \text { adults })\end{array}$ \\
\hline$\leq 5 \mathrm{mmHg}$ & Low responder & $39(89 \%)$ & $53(66 \cdot 2 \%)$ \\
$6-15 \mathrm{mmHg}$ & Intermediate & $4(9 \%)$ & $23(28 \cdot 8 \%)$ \\
$16+\mathrm{mmHg}$ & High & $1(2 \%)$ & $4(5 \%)$ \\
\hline
\end{tabular}

$0 \cdot 1 \%$ ophthalmic solution was applied to both eyes 4 times daily for 6 weeks. The intraocular pressure was measured every 2 weeks with the Goldmann applanation tonometer. A pressure rise of up to $5 \mathrm{mmHg}$ was considered a low response, $6-15 \mathrm{mmHg}$ intermediate, and $16 \mathrm{mmHg}$ and above high. ${ }^{1}$ The statistical analysis was by the chi-square method.

\section{Results}

Thirty-nine children $(89 \%)$ showed either no rise in IOP or a rise of less than $6.0 \mathrm{mmHg}$. Four children showed an increase of 6-15 mmHg. Only 1 child was found to have an increase in his intraocular pressure more than $16 \mathrm{mmHg}(2 \%)$. The results are shown in Table 1.

\section{Discussion}

Comparing the results in our children with those from Armaly's normal adults (Table 1) shows the differences in the steroid response to be not significant. However, if one considers the intermediate and high responders together (5 out of 44 children $(11 \%)$ and 27 out of $80(33.8 \%)$ adults) this difference is statistically significant $(\mathbf{P}<\mathbf{0 . 0 1})$. In other 
words, our results indicate that the hypertensive response to steroid instillation in our sample of children is lower than in normal adults. In children of parents suffering from glaucoma Francois $^{3}$ reported $34 \%$ positive responders (intermediate and high).

It should be noted that the average initial IOP found in our children was $11 \cdot 2 \pm 2 \cdot 0$, which is below the accepted normal IOP in adults $16 \cdot 0 \pm 3 \cdot 0 .{ }^{4}$ This finding might explain the lower steroid response in children than in normal adults, as a higher initial IOP is expected later in life. This may produce an increase in the steroid responsiveness also.

Although these 3 groups were differentiated on the basis of the magnitude of pressure rise, the time of pressure rise was also different, and it is of clinical significance. Group 1, the low responders, showed a slight pressure rise at the end of 2 weeks, and the pressure remained stabilised afterwards. In groups 2 and $3(11 \%)$ the pressure rose continuously with further treatment. The clinical implication of this is that a child who has received topical corti- costeroid treatment for a month but still has pressures below $21 \mathrm{mmHg}$ is unlikely to have a further increase in his or her intraocular pressure. Should the pressure be above $21 \mathrm{mmHg}$ at the end of the first month, subsequent steroid therapy should include careful monitoring of the intraocular pressure.

These results do not differ substantially from previously reported observations on time-dependent IOP raised in normal adults. ${ }^{1}$

We thank Mrs Bilha Savell for her technical assistance.

References

${ }^{1}$ Armaly MF. Statistical attributes of the steroid hypertensive response in the clinically normal eye. Invest Ophthalmol Visual Sci 1965; 4: 187-9.

${ }^{2}$ Armaly MF. Inheritance of dexamethasone hypertension and glaucoma. Arch Ophthalmol 1967; 77: 747-51.

${ }^{3}$ Francois J. Corticosteroid glaucoma. Ann Ophthalmol 1977; 9: 1075-80.

'Graham PA. Epidemiology of simple glaucoma and ocular hypertension. Br J Ophthalmol 1972; 56: 223-9. 